\title{
Immobilized thermolysin for highly efficient production of low-molecular-weight protamine-An attractive cell-penetrating peptide for macromolecular drug delivery applications
}

\author{
Allan E. David, ${ }^{1,2}$ Junbo Gong, ${ }^{3}$ Beata Chertok, ${ }^{3}$ Roman C. Domszy, ${ }^{2}$ Cheol Moon, ${ }^{3}$ \\ Yoon Shin Park, ${ }^{3}$ Nam Sun Wang, ${ }^{1}$ Arthur J. Yang, ${ }^{2}$ Victor C. Yang ${ }^{3,4}$ \\ ${ }^{1}$ Department of Chemical Engineering, A. James Clark School of Engineering, University of Maryland, \\ College Park, Maryland 20742 \\ ${ }^{2}$ Industrial Science \& Technology Network (ISTN) Inc., York, Pennsylvania 17404 \\ ${ }^{3}$ Department of Pharmaceutical Science, University of Michigan, Ann Arbor, Michigan 48109 \\ ${ }^{4}$ Tianjin Key Laboratory on Technologies Enabling Development of Clinical Therapeutics and Diagnostics, \\ School of Pharmacy, Tianjin Medical University, Tianjin 300070, China
}

Received 8 March 2011; revised 30 June 2011; accepted 17 July 2011

Published online 31 October 2011 in Wiley Online Library (wileyonlinelibrary.com). DOI: 10.1002/jbm.a.33244

\begin{abstract}
Macromolecules present a remarkable potential as future therapeutics. However, their translation into clinical practice has been hampered by an inherently low bioavailability. Cell-penetrating peptides (CPP) have been recently shown to significantly improve on the bioavailability of macromolecules. Yet, the high cost associated with development and production of these peptides is a major factor hindering their rapid deployment beyond the laboratory. Here, we describe a facile and robust methodology for efficient and large-scale production of low-molecular-weight protamine-a potent CPP of great clinical potential. Our methodology is based on the immobilization of thermolysin, an enzyme catalyzing digestion of native protamine, on chemically surface-modified gels produced by silica sol-gel chemistry.
\end{abstract}

Thermolysin was immobilized at extremely high matrix loading of $733 \mathrm{mg} / \mathrm{g}$ matrix and exhibited good thermal and $\mathrm{pH}$ stability, indicating robustness with respect to processing conditions. The mechanical properties of the silica matrix further allowed utilization of the immobilized thermolysin in both batch and packed-bed reactor systems to produce the LMWP peptide in high yields. Results presented here are of high significance as this efficient and cost-effective production of high purity LMWP could enable clinical translation of many potential macromolecular drugs. (c) 2011 Wiley Periodicals, Inc. J Biomed Mater Res Part A: 100A: 211-219, 2012.

Key Words: enzyme immobilization, sol-gel silica, thermolysin, peptide synthesis, protamine, LMWP, cell-penetrating peptide

How to cite this article: David AE, Gong J, Chertok B, Domszy RC, Moon C, Park YS, Wang NS, Yang AJ, Yang VC. 2012. Immobilized thermolysin for highly efficient production of low-molecular-weight protamine-An attractive cell-penetrating peptide for macromolecular drug delivery applications. J Biomed Mater Res Part A 2012:100A:211-219.

\section{INTRODUCTION}

An increased understanding of biological pathways and unraveling of the human genome over the past decade have elucidated the many factors that affect disease progression. This new knowledge has in turn highlighted many new potential targets for the treatment of disease. Although small molecule drugs have been utilized for centuries to treat various ailments, their lack of specificity often leads to serious side effects. Biomacromolecules (e.g., proteins and oligonucleotides), on the other hand, can offer unmatched target specificity and selectivity. The exquisite specificity of oligonucleotides, for example, has been shown, ${ }^{1,2}$ with the potential ability to even discriminate between mRNAs differing in only a single base pair. ${ }^{3}$ Clinical use of macromolecular drugs, however, is hindered by several barriers, including: (1) their limited bioavailability, (2) high production costs, and (3) instability in biological fluids. Additionally, because the majority of these molecules cannot penetrate the cellular membrane, additional hurdles exist for macromolecules that target intracellular components. ${ }^{4}$

The bioavailability of macromolecular therapeutics has been enhanced through conjugation with the recently discovered class of cell-penetrating peptides (CPP). ${ }^{5}$ Although the mechanism is still unclear, these CPPs have demonstrated an

Correspondence to: A. J. Yang; e-mail: ajyang@istninc.com or V. C. Yang; e-mail: vcyang@umich.edu

Contract grant sponsor: National Institutes of Health (NIH); contract grant numbers: R44 Grant HL059705, R01 Grants CA114612, NS066945, R43DK67723

Contract grant sponsor: Industrial Science and Technology Network (ISTN) Inc

Contract grant sponsor: WCU project of South Korea; contract grant number: R31-2008-000-10103-01

Contract grant sponsor: National Basic Research Program of China (973 Program); contract grant number: 2007CB935800 
ability to ferry large proteins (e.g., $\beta$-galactosidase) into many different cell types and even facilitate crossing of the blood-brain barrier. ${ }^{6}$ Additionally, CPPs have been shown to enhance the oral bioavailability of insulin, ${ }^{7}$ increase transfection efficiency of siRNAs, ${ }^{8}$ and even improve the intracellular uptake of nanoparticulate drug carriers. ${ }^{9}$ Although the potential for these peptides to enhance delivery of macromolecular drugs is tremendous, this has yet to be realized in clinical practice. ${ }^{10,11}$ It has been suggested that technical challenges, risk mitigation, and development costs could all be factors hindering the overall development of CPP-drug conjugates. ${ }^{12,13}$

CPPs are typically produced by recombinant or solidphase synthesis methods, and the raw material cost and the extensive purification requirements make the cost prohibitively high for large-scale utilization. For example, the current commercial price for milligram quantities of a peptide of $>98 \%$ purity (greater purity improves chances of regulatory approval) is in the range of US $\$ 25-\$ 50$ per amino acid residue. This puts the CPP peptide on the same scale, or above, in magnitude of cost as many of the macromolecular drugs themselves. Development of an inexpensive, high-purity $\mathrm{CPP}$, which exhibits a proven safety profile, could be the necessary impetus for carrying many of the promising macromolecular drugs into clinical translation. ${ }^{13}$

The development of low-molecular-weight protamine (LMWP), from the clinically utilized drug protamine, has been previously described. ${ }^{14}$ Although initially developed for heparin reversal, ${ }^{15,16}$ the structural similarities of LMWP with HIV-TAT prompted evaluation of its cell-penetrating properties. The resulting studies showed that LMWP enhanced intracellular delivery of DNA, ${ }^{17,18}$ siRNA, ${ }^{19}$ therapeutic proteins, $^{20,21}$ drug-conjugated polymers, ${ }^{22,23}$ and even nanoparticles. ${ }^{24}$ LMWPs potent cell-penetrating properties, combined with its proven nontoxic and nonimmunogenic profile, ${ }^{25-27}$ exceeding that of the FDA-approved protamine, make it an attractive candidate for clinical use in improving macromolecular drug efficacy. We here further demonstrate that the LMWP peptide can be efficiently produced on a large scale, at high purity, and at relatively low costs-transforming it from just another interesting laboratory compound into one that is commercially viable for eventual clinical translation.

Production of LMWP is achieved by thermolysin-catalyzed digestion of native protamine. Thermolysin (EC 3.4.24.27) is a bacterial, zinc-dependent neutral metalloprotease that acts as a catalyst for the hydrolysis/synthesis of peptide bonds, with high specificity for amino acids containing bulky, hydrophobic side chains. Thermolysin-mediated digestion of protamine results in the formation of several peptides of varying lengths and amino acid compositions, which have been labeled sequentially from TDSP1 to TDSP5 based on their increasing heparin binding strength. ${ }^{28}$ TDSP5, the largest fragment with an amino acid sequence of VSRRRRRRGGRRRR, is the peptide of interest here and any reference to LMWP will henceforth indicate the TDSP5 fragment.

Previously, we reported the immobilization of invertase on amino-chemically surface-modified gel (N-CSMG) pro-

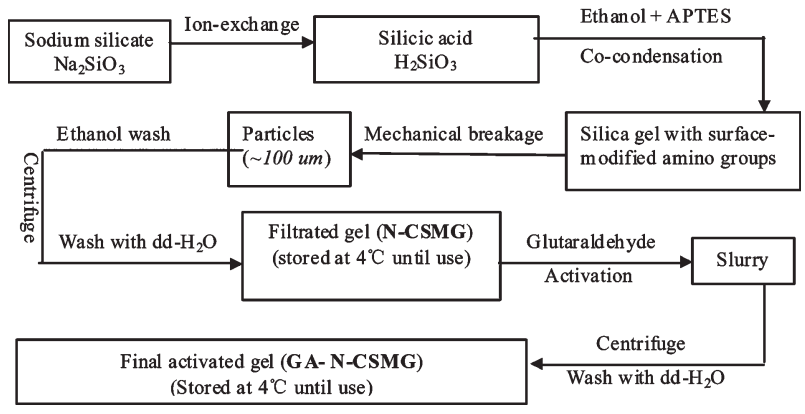

SCHEME 1. Procedure for preparation of amino-chemically surface modified gel (N-CSMG) and glutaraldehyde-activated N-CSMG (GA-NCSMG). dd = double-distilled.

duced by silica sol-gel chemistry. ${ }^{29}$ In that work, it was shown that an extremely high enzyme loading, $723 \mathrm{mg}$ invertase/g matrix, could be achieved with complete retention of the enzyme's catalytic efficiency $\left(V_{\max } / K_{\mathrm{m}}\right)$. Because $\mathrm{N}$-CSMG displayed considerable promise as an immobilization matrix, we turned our efforts to the immobilization of thermolysin for the production of LMWP. The immobilized thermolysin is characterized by determination of the $\mathrm{pH}$ and temperature-dependent activity profiles in comparison with those of free thermolysin. We then examine the stability of the immobilized thermolysin in both batch and packed-bed reactor (PBR) systems and demonstrate its potential for large-scale peptide production.

\section{MATERIALS AND METHODS \\ Materials}

Thermolysin (Type X, lyophilized powder, 50-100 units/mg protein) from Bacillus thermoproteolyticus rokko, glutaraldehyde (25 wt \% in water), protamine sulfate salt from salmon (Grade X), trichloroacetic acid (98\% pure), 3-aminopropyltriethoxysilane (APTES), and azocasein were purchased from Sigma-Aldrich (St. Louis, MO) and used as supplied. Sodium silicate (N-type) was purchased from PQ Corporation (Valley Forge, PA). All other reagents were of analytical grade, and water was distilled and deionized. Hi-Trap Heparin columns were purchased from GE Life Sciences (Piscataway, NJ).

\section{Methods}

Synthesis of N-CSMG and glutaraldehyde-activated silica gel. The sol-gel process used for production of N-CSMG and glutaraldehyde-activated silica gel (GA-N-CSMG) were as previously described ${ }^{29}$ and is depicted in Scheme 1. Briefly, silicic acid $\left(\mathrm{H}_{2} \mathrm{SiO}_{3}\right)$ was produced from sodium silicate $\left(\mathrm{Na}_{2} \mathrm{SiO}_{3}\right)$ using an ion exchange process. The silicic acid was then mixed with APTES, in the presence of ethanol as cosolvent, to produce amino-functionalized, monolithic gels (N-CSMG). The N-CSMG gel was then mechanically ground and successively washed with ethanol and then $\mathrm{ddH}_{2} \mathrm{O}$ to remove any unreacted monomers. The washed N-CSMG was then activated with 0.5 wt \% glutaraldehyde (GA), a homobifunctional crosslinker, to produce GA-N-CSMG. The resulting GA-activated gel was separated by filter paper and washed several times with $\mathrm{ddH}_{2} \mathrm{O}$ to remove any excess 
GA. The washed gel was stored at $4^{\circ} \mathrm{C}$, for up to 1 month, until used.

Immobilization of thermolysin on GA-N-CSMG. To immobilize thermolysin, $500 \mathrm{mg}$ of GA-N-CSMG were weighed into a $50-\mathrm{mL}$ conical vial. Twenty milliliters of $2 \mathrm{~g} / \mathrm{L}$ thermolysin, in $50 \mathrm{~m} M$ phosphate buffer at $\mathrm{pH} 7.0$, were introduced to the vial and the suspension stirred at $4^{\circ} \mathrm{C}$ for $12 \mathrm{~h}$. The suspension was then centrifuged at $10,000 \times \mathrm{g}$ for $10 \mathrm{~min}$ and the supernatant, containing free thermolysin, removed. The thermolysin-immobilized gel was washed three times with $20 \mathrm{~mL}$ of $100 \mathrm{mM}$ phosphate buffer (pH 7.0) and centrifuged between each wash. Protein content in the supernatant was followed using the Bradford assay, ${ }^{30}$ and three washes were found to be adequate for removal of all free enzyme. Measured concentrations were used to determine enzyme loading on the GA-N-CSMG gels by mass balance. The immobilized thermolysin was stored in $20 \mathrm{mM}$ phosphate buffer ( $\mathrm{pH} \mathrm{7.0)}$ ) at $4^{\circ} \mathrm{C}$ until use.

Measurement of thermolysin activity. Thermolysin activity was measured colorimetrically with azocasein as substrate. The enzyme, free or immobilized, was incubated with $4 \mathrm{~mL}$ of 0.5 wt \% azocasein solution. Proteolysis of the casein releases a soluble dye into solution, which can be detected by measuring absorbance at $440 \mathrm{~nm}$. The reaction was stopped by addition of $500 \mu \mathrm{L}$ of $15 \%$ trichloroacetic acid to a $1 \mathrm{~mL}$ aliquot of the reaction solution, which induces precipitation of any undigested azocasein. The precipitate was then removed from solution by centrifugation at $12,000 \times \mathrm{g}$ for 5 min. Enzymatic activity is proportional to the dye remaining in solution. One unit of thermolysin activity was taken to equal the amount of enzyme producing an increase of 0.1 absorbance units/min at $440 \mathrm{~nm}$. All activity tests were conducted in triplicate and are reported as mean \pm S.D.

Effect of pH on immobilized thermolysin activity. The $\mathrm{pH}-$ dependant activity profiles of both the immobilized- and free thermolysin were determined using the procedure described above, at $37^{\circ} \mathrm{C}$ in $50 \mathrm{mM}$ buffered solutions. An acetate buffer was used for $\mathrm{pH} 5.0$, phosphate buffer for $\mathrm{pH}$ 6.0 and 6.5, tris(hydroxymethyl)aminomethane (TRIS)/HCl was used for $\mathrm{pH} 7.0,7.5$, and 8.0, and TRIS/NaOH was used for $\mathrm{pH} 9.0$.

Effect of temperature on immobilized thermolysin activity. The effect of temperature on both free- and immobilized thermolysin activity was determined by measuring the hydrolysis of azocasein at temperatures ranging from 25 to $85^{\circ} \mathrm{C}$. Enzymatic activity was measured as described above, using a 0.5 wt \% azocasein solution buffered with $50 \mathrm{mM}$ TRIS/HCl (pH 7.0).

Batch production of LMWP by immobilized thermolysin. Immobilized thermolysin (50 mg matrix) was introduced to $100 \mathrm{~mL}$ of a magnetically stirred, thermostated solution consisting of $10 \mathrm{mg} / \mathrm{mL}$ protamine, $2 \mathrm{mM} \mathrm{CaCl}$, and $50 \mathrm{mM}$ Tris/HCl buffer (pH 7.4). Protamine hydrolysis was allowed to proceed for specified time intervals and the reaction then halted by addition of ethylenediaminetetraacetic acid, which chelates the $\mathrm{Ca}^{2+}$ cofactor required for enzymatic activity. After filtration with a $0.22-\mu \mathrm{m}$ syringe filter, to remove the immobilized thermolysin, peptide fragments in a sample of the reaction solution were analyzed by HPLC, as described in Section "Analysis of LMWP production by HPLC." Production efficiency was determined by the fractional area of the LMWP peak relative to all other peaks in the chromatograph. Batch stability of the immobilized thermolysin was determined by measuring the LMWP produced in sequential batches at reaction temperatures ranging from 35 to $55^{\circ} \mathrm{C}$.

Immobilized thermolysin PBR for continuous LMWP production. The production of LMWP by immobilized thermolysin was also analyzed in a PBR. The PBR consisted simply of a $0.22-\mu \mathrm{m}$ syringe filter (Fisher brand, Cat. No. 09-719A) loaded with $45 \mathrm{mg}$ of silica matrix containing $33 \mathrm{mg}$ of immobilized thermolysin. Protamine solution, $10 \mathrm{mg} / \mathrm{mL}$ buffered at pH 7.5 (50 mM TRIS/HCl, $2 \mathrm{mM}$ $\mathrm{CaCl}_{2}$ ), was introduced through the filter injection port with a peristaltic pump at a flow rate of $1 \mathrm{~mL} / \mathrm{min}$. Although the $0.22-\mu \mathrm{m}$ membrane retained the silica gel with the immobilized thermolysin, the digested protamine solution that passed through was collected and then analyzed by HPLC. The PBR and feed line were immersed in a $45^{\circ} \mathrm{C}$ water bath to maintain reaction temperature.

Analysis of LMWP production by HPLC. A HPLC gradient system, consisting of dual Alltech Model 526 pumps (Grace, Deerfield, IL), a Linear UVIS200 detector (Grace, Deerfield, IL), and a PeakSimple Chromatography Data System Model 202 (SRI Instruments, Torrance, CA) was utilized to monitor the peptides produced during enzymatic digestion of protamine, as previously described. ${ }^{28}$ Briefly, the various peptides were separated by their heparin binding affinity, using a $1 \mathrm{~mL}$ HiTrap Heparin HP column (GE Healthcare, Piscataway, NJ). The system was equilibrated with $50 \mathrm{mM}$ TRIS/HCl (pH 7.5) before injection of test sample and the peptides eluted with a linear $\mathrm{NaCl}$ gradient. Peptide fractions were monitored by absorbance at $214 \mathrm{~nm}$.

\section{RESULTS AND DISCUSSIONS}

Development of silica gels for high-capacity enzyme immobilization

Enzymes are catalytic proteins that can substantially increase reaction rates and improve product yields, while operating under mild reaction conditions. They have, therefore, attracted much attention for the development of "green" chemistry production processes. Although the high production efficiency has encouraged the integration of enzymes in industrial processes, these efforts have been hampered by the short half-life and relatively high cost of enzymes. These issues could be mitigated through the immobilization of the enzyme on a solid matrix, allowing easy recovery and repeated use of the enzyme, which reduces operational costs. Enzyme immobilization has also been shown to provide the additional advantage of 


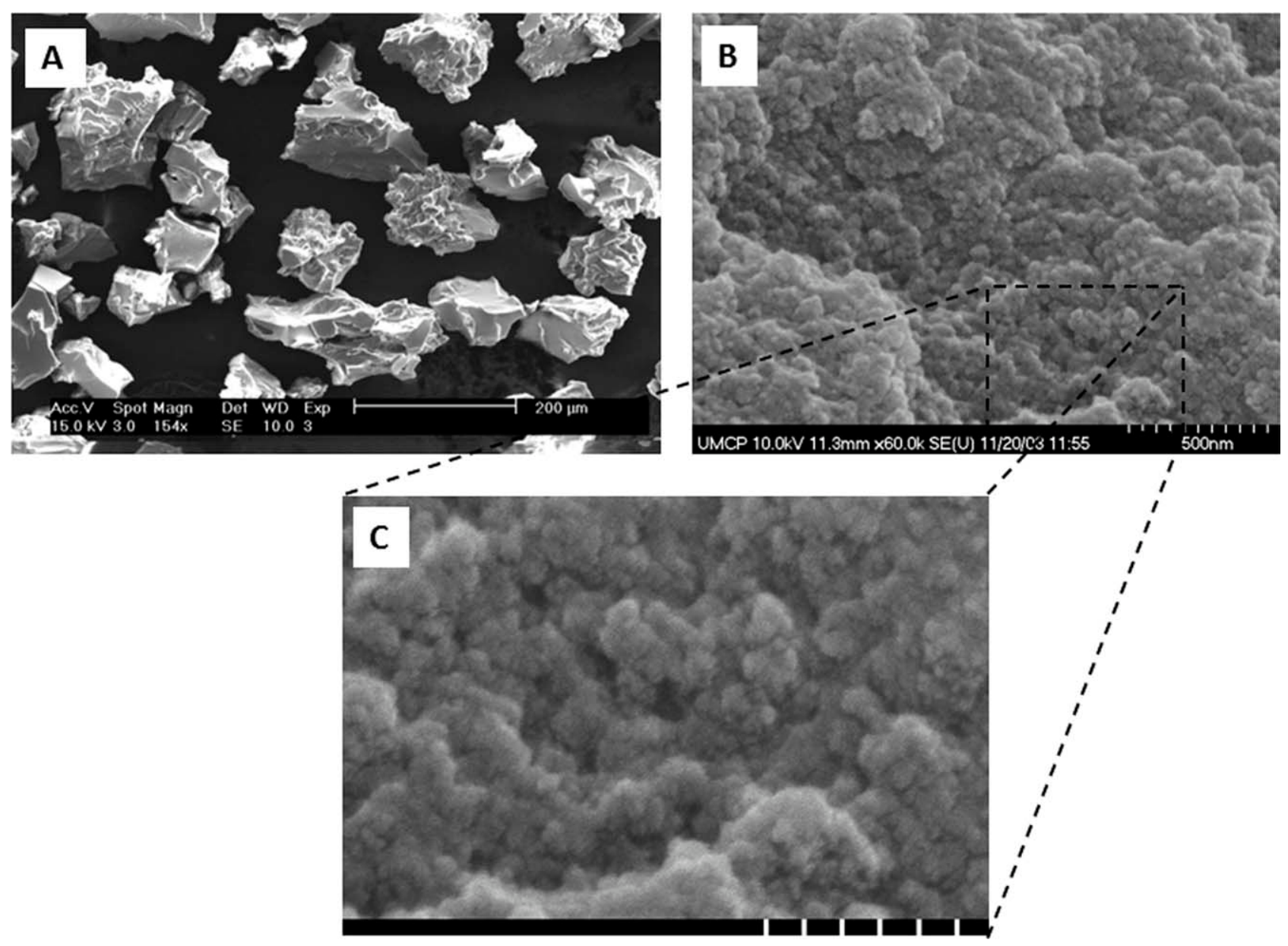

FIGURE 1. Visualization of supercritically dried N-CSMG by SEM under $(A)$ low $(\times 154)$ and $(B)$ high $(\times 60 k)$ magnification revealed a rough surface which likely contributed to the observed high-specific surface area. Closer inspection (C) reveals the porous surface with the largest of pores having diameters of $\sim 50 \mathrm{~nm}$ (white scales at $50 \mathrm{~nm}$ intervals).

enhanced stability under both operational and storage conditions. ${ }^{31}$

The immobilization matrix must meet several important specifications to achieve efficient enzyme immobilization. Mechanical and chemical stability are critical for insuring reactor integrity during long-term operations. In addition, large surface areas and high porosity are desirable as they, respectively, enable high enzyme loadings and free diffusion of substrate/product-together yielding higher production rates and efficiency. ${ }^{32}$ Maintenance of porosity and surface area can be challenging with nanoporous matrices because of capillary stresses, which are inversely proportional to pore radius, that can crack and collapse the porous structure. With silica gels, widely utilized as an enzyme immobilization matrix, this challenge is especially pronounced. Silica gels contain a considerable amount of silanol groups which, while providing a valuable resource for surface modification, ${ }^{33,34}$ can undergo cocondensation reactions resulting in an irreversible loss of porosity. ${ }^{35}$ Silanol cocondensation also reduces the surface area available for enzyme immobilization. To enable efficient enzyme immobilization on a silica gel matrix, we first sought to develop a method for reduc- tion of gel shrinkage. We hypothesized that the shrinkage of gels can be minimized through modification of the silica gel while in its wet state, effectively occupying the silanol groups and preventing their cross-reaction. The successful utilization of this methodology and characterization of the resulting enzyme immobilization matrix for high loading of thermolysin are here described.

Synthesis of high-porosity silica gels using sol-gel chemistry. $\mathrm{N}-\mathrm{CSMG}$ gels were produced according to the procedure outlined in Section "Synthesis of N-CSMG and glutaraldehyde-activated silica gel." SEM images of N-CSMG dried with supercritical $\mathrm{CO}_{2}$ show that the material contains a distribution of pore sizes with the largest pores having diameters of $\sim 50 \mathrm{~nm}$, see Figure 1 . Also seen is the rough surface texture, which provides the high surface area for enzyme immobilization. N-CSMG was further reacted with GA to produce GA-N-CSMG. Confocal fluorescence microscope (Olympus FV-500 with a HeNeG laser) imaging of the fluorescent Schiff-base, formed when GA reacts with amino groups on the N-CSMG surface, suggested the homogenous distribution of both the amino surface modification and the GA 
crosslinker. $^{36}$ A homogenous distribution of the reactive groups is important to achieving uniform and maximum distribution of the immobilized enzyme.

Maximum thermolysin loading on GA-N-CSMG. Thermolysin was immobilized onto GA-N-CSMG as described in above Section "Immobilization of thermolysin on GA-N-CSMG." Mass balance results indicated that $733 \pm 13 \mathrm{mg}$ of thermolysin was immobilized per gram of GA-N-CSMG. This is significantly higher than the maximum loading of $11.6 \mathrm{mg} / \mathrm{g}$ carrier reported for GA-activated PVA cyrogel, ${ }^{37} 27 \mathrm{mg} / \mathrm{g}$ polymer with a glycidyl methacrylate copolymer, ${ }^{38}$ and 36 $\mathrm{mg} / \mathrm{mL}$ obtained with agarose gel. ${ }^{39}$ This exceptionally high loading validated our hypothesis that wet-state modification of nanoporous gels could dramatically improve immobilization loadings. Additonally, the high enzyme loading capacity of the GA-N-CSMG allows for potential reactor miniaturization and the continuous production of peptides with therapeutic applications, as discussed later.

\section{Characterization of immobilized thermolysin and optimization of conditions for peptide production}

As with all proteins, enzyme conformation-which is critical for enzymatic activity-is susceptible to changes in the microenvironment, including both $\mathrm{pH}$ and temperature effects. This is especially true for immobilized enzymes, which can adopt varying tertiary configurations due to interactions with the solid matrix, resulting in changes in $\mathrm{pH}$ - and temperature-dependent activities compared to the free enzyme. Measurement of enzymatic activity in conditions of varying $\mathrm{pH}$ and temperature can not only provide insight into the relative importance of reaction mechanisms (e.g., activation energy and diffusion limitations) but also enable the well-informed selection of initial conditions for production process optimizations. The following sections describe the characterization of immobilized thermolysin activity as a function of both $\mathrm{pH}$ and temperature. Optimum conditions derived from these results are then utilized to measure the time-dependent production of LMWP in a batch reactor, as well as the temperature stability of the immobilized thermolysin.

Effect of $\mathrm{pH}$ on the activity of immobilized thermolysin. Shifts in optimum $\mathrm{pH}$ of up to 2 units for immobilized enzyme activities, compared to the free enzyme, can occur depending on both enzyme and matrix properties. ${ }^{40}$ As seen in Figure 2, however, no $\mathrm{pH}$ shift was observed with the immobilization of thermolysin on GA-N-CSMG, with both the immobilized and free thermolysin exhibiting maximum activity at $\mathrm{pH}$ 7.5. This is in contrast to our previous work with GA-N-CSMG, where a 1.0 unit shift to lower $\mathrm{pH}$ was observed for immobilized invertase; ${ }^{29}$ this was attributed to generation of a higher $\mathrm{pH}$ microenvironment close to the surface by the basic, amino-functionalized matrix. Changes in $\mathrm{pH}$ typically lead to breaking of ionic bonds within the enzyme and a resulting change in tertiary structure and enzymatic activity. It is possible that thermolysin, with its enhanced conformational stability compared to other

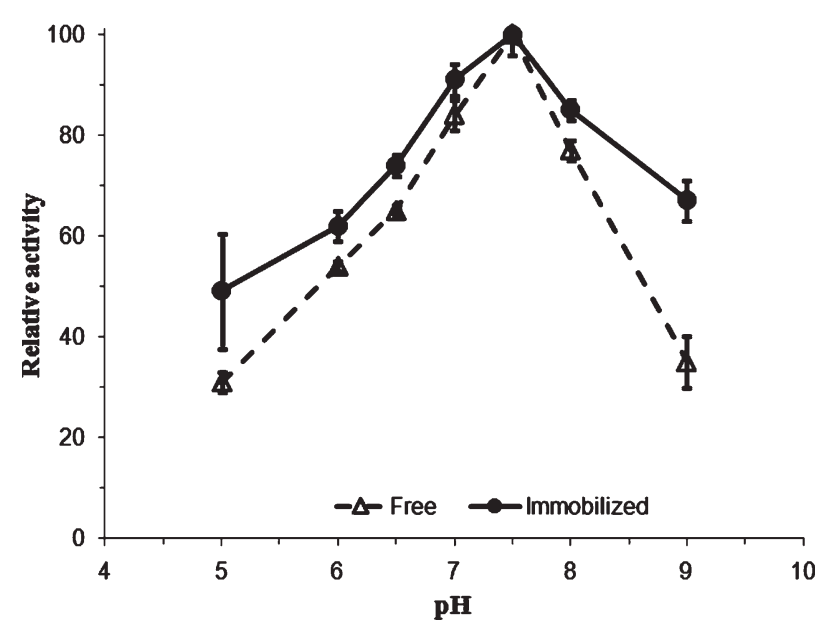

FIGURE 2. Effect of $\mathrm{pH}$ on relative activity of free- and immobilized thermolysin. Although no shift in optimum $\mathrm{pH}$ was observed, the immobilized thermolysin retained greater activity, compared to free thermolysin, at deviations away from the optimum of $\mathrm{pH}$ 7.5. Data shown as mean \pm S.D. $(n=3)$ relative activity, as determined for each enzyme formulation independently.

enzymes, ${ }^{41}$ is more resistant to denaturing effects of $\mathrm{pH}$. Additionally, as the azocasein substrate utilized in this study is much larger than the previously used sucrose, it is also possible that diffusional limitations of azocasein into the porous matrix, as the rate-limiting step, masked the effects of $\mathrm{pH}$. More detailed studies, however, are required to fully elucidate the mechanism.

The current data, however, clearly indicate that the activity of immobilized thermolysin is affected to a lesser degree, compared to free thermolysin, by changes in $\mathrm{pH}$ away from the optimum. Others have indicated that such broadening of the $\mathrm{pH}$ profile occurs due to a conservation of the optimum $\mathrm{pH}$ within the matrix. ${ }^{42}$ Broadening of $\mathrm{pH}$ profiles has also been attributed to diffusional limitations of substrate/product through the matrix or to secondary interactions between the enzyme and the matrix. ${ }^{43}$

Effect of temperature on the activity of immobilized thermolysin. The effect of temperature, ranging from 25 to $85^{\circ} \mathrm{C}$, on the activity of both free and immobilized thermolysin was measured using azocasein as substrate. As seen in Figure 3, the free enzyme showed an exponential increase in activity up to $65^{\circ} \mathrm{C}$ and a slower, linear increase at higher temperatures up to $85^{\circ} \mathrm{C}$. The immobilized thermolysin, on the other hand, exhibited an exponential increase in enzymatic activity up to the maximum measured temperature of $85^{\circ} \mathrm{C}$.

According to the collision theory of chemical reactions, molecules exist with a distribution of energies, and a product is formed only when collision occurs between molecules having energy greater than a potential energy barrier-the activation energy $\left(E_{\mathrm{a}}\right)$. The number of molecules possessing this energy follows a Boltzmann distribution-a relationship used to develop the Arrhenius equation (shown here in logarithmic form): 


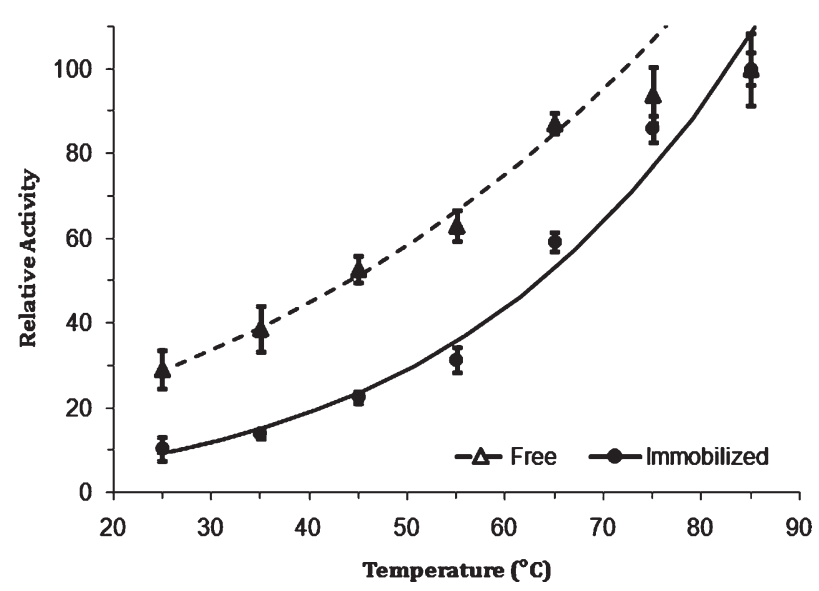

FIGURE 3. Relative activity profiles for free- and immobilized thermolysin as a function of reaction temperature. Trend lines for each data set are drawn based on calculations using the Arrhenius equation, with activation energy $\left(E_{\mathrm{a}}\right)$ and pre-exponential factor $(A)$ obtained by fitting of data to the equation. Data shown as mean \pm S.D. $(n=3)$ relative activity, as determined for each enzyme formulation independently.

$$
\ln k=\ln A-\frac{E_{\mathrm{a}}}{R T}
$$

where $k$ is the rate constant, $A$ the pre-exponential factor, $E_{\mathrm{a}}$ is the activation energy, $R$ the gas constant, and $T$ is the absolute temperature. Plotting $\ln k$ versus $(1 / T)$ yields a straight line with a slope equal to $-E_{\mathrm{a}} / R$ and intercept of $\ln$ $A$. Such analysis of the data revealed that the free thermolysin followed Arrhenius kinetics at temperatures between 25 and $65^{\circ} \mathrm{C}$, while other factors apparently contributed to non-Arrhenius behavior observed at higher temperatures. The temperature-dependent activity profiles of enzymatic reactions are primarily governed by: (1) the increase in reaction rates with temperature, according to the Arrhenius equation and (2) thermal denaturing of enzymes and its resulting loss of activity. It, therefore, appears likely that some free thermolysin activity is lost at temperatures above $65^{\circ} \mathrm{C}$ because of thermal inactivation. This correlates well with literature, which observed no variation in the crystal structure of thermolysin at temperatures up to $65^{\circ} \mathrm{C} .{ }^{41}$ The immobilized thermolysin, on the other hand, displayed Arrhenius kinetics up to a temperature of $85^{\circ} \mathrm{C}$, suggesting a greater thermal stability compared to the free form. It should be pointed out that this data gives an indication of the enzyme's short-term stability. The optimization of a production process, however, also requires the consideration of long-term stability, which is discussed in following sections.

TABLE I. Comparison of Activation Energy and Pre-exponential Factor of Free- and Immobilized Thermolysin

\begin{tabular}{lcc}
\hline & $\begin{array}{c}\text { Activation } \\
\text { Energy }(\mathrm{kJ} / \mathrm{mol})\end{array}$ & $\begin{array}{c}\text { Pre-exponential } \\
\text { Factor (U/g Protein) }\end{array}$ \\
\hline Free thermolysin & $22.5 \pm 1.0$ & $1.06 \times 10^{8}$ \\
Immobilized & $36.1 \pm 2.0$ & $7.53 \times 10^{9}$ \\
\hline
\end{tabular}

Results in Table I show the extrapolated activation energies and pre-exponential factors, determined using only data within the Arrhenius regime, for free and immobilized thermolysin. Free thermolysin displayed $E_{\mathrm{a}}$ and $A$ values of $22.5 \mathrm{~kJ} / \mathrm{mol}$ and $1.06 \times 10^{8}$, respectively. The apparent activation energy of the immobilized thermolysin at $36.1 \mathrm{~kJ} / \mathrm{mol}$ was significantly higher than that of the free form; the pre-exponential factor of $7.53 \times 10^{9}$ is also increased. Higher activation energy for the immobilized thermolysin could be attributed to conformational changes brought upon by the immobilization or to potential steric hindrance of the enzyme's active site. Further studies, however, are required to determine the exact cause of this change in the activation energy.

Kinetics of protamine digestion by immobilized thermolysin. With the immobilized enzyme activity characterized in terms of both the $\mathrm{pH}$ and temperature effects, we then focused on the hydrolysis of protamine for the production of LMWP. Protamine hydrolysis by immobilized thermolysin, in a batch reactor at $40^{\circ} \mathrm{C}$, and the subsequent formation of smaller peptides is shown in Figure 4. The zero time point profile shows the presence of a single peak, corresponding to protamine, eluting at a salt concentration of $1.2 \mathrm{M}$. The appearance of several early eluting peaks and reduction of the protamine peak are seen as the reaction is allowed to

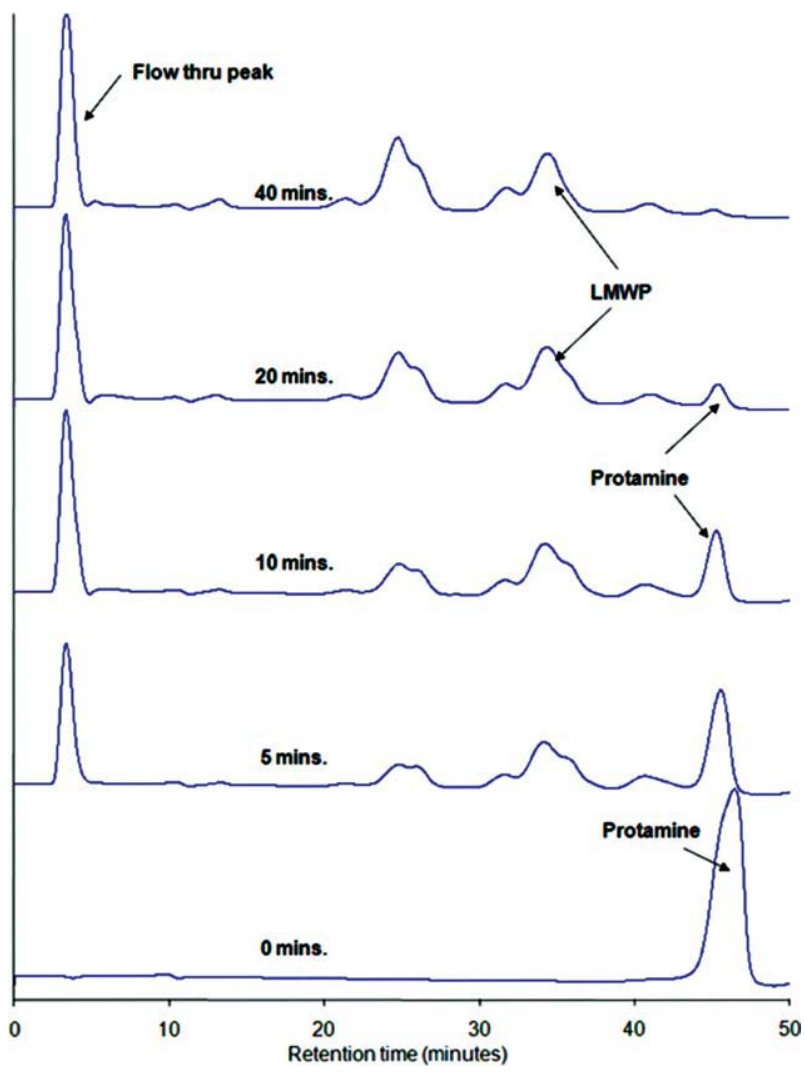

FIGURE 4. Heparin-affinity elution profiles of protamine fragments, digested by immobilized thermolysin, illustrating the dependence of LMWP production on reaction time. [Color figure can be viewed in the online issue, which is available at wileyonlinelibrary.com.] 


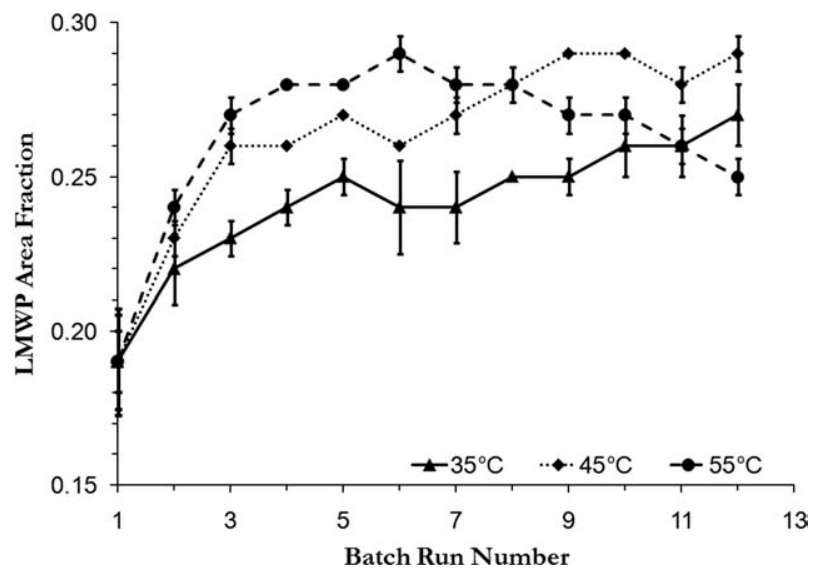

FIGURE 5. Effect of reaction temperature on LMWP yield. Area fraction of the LMWP peak relative to the total area of all peaks was determined as eluted by salt gradient from a heparin column. Data shown as mean \pm S.D. $(n=3)$.

proceed for up to $40 \mathrm{~min}$. The amino acid sequences for each of these peaks have been determined and are reported elsewhere. ${ }^{28}$ It can be seen that hydrolysis of protamine occurs rapidly over the first $5 \mathrm{~min}$ and is complete by $40 \mathrm{~min}$. Some peaks were observed to be transient, appearing early in the reaction and then disappearing as the hydrolysis neared completion, such as the right shoulder on the LMWP peak in the 5, 10, and 20 min chromatographs. The size of the LMWP peak remained relatively constant at even higher incubation times up to $1.5 \mathrm{~h}$ (data not shown), indicating that the produced peptide is relatively stable to hydrolysis by thermolysin.

Effect of temperature on LMWP production by immobilized thermolysin. The long-term effect of temperature on immobilized thermolysin activity was followed by determining the LMWP yield in serial batch reactions conducted at temperatures in the range of $35-55^{\circ} \mathrm{C}$. Figure 5 displays the LMWP production ratio obtained during 12 serial, batch runs with immobilized thermolysin at temperatures of 35 , 45 , and $55^{\circ} \mathrm{C}$. After completion of each reaction, the gel suspension was centrifuged to recover the immobilized thermolysin, followed by washing with buffer solution. The immobilized thermolysin was then reintroduced to a fresh protamine solution and the reaction repeated.

At each of the temperatures tested, the LMWP peak is initially about $19 \%$ of total peak area for the first batch run and continually increases over subsequent run cycles to a maximum of about $29 \%$. This maximum is reached faster at the higher run temperatures; at $55^{\circ} \mathrm{C}$, this level was achieved after only 6 runs, whereas 9 and 12 cycles were required at reaction temperatures of $45^{\circ} \mathrm{C}$ and $35^{\circ} \mathrm{C}$, respectively. Close examination of all batch-to-batch peak areas (data not shown) revealed that the increase in the LMWP peak area, observed in subsequent batch numbers, was accompanied with a decrease in area of the peak eluting at flow-through (first peak observed in chromatographs of Fig. 4), which contained non-heparin binding species. As the enzyme preparation used in this work was not pure thermolysin but contained some contaminant proteins, it is possible that the presence of other proteases (e.g., trypsin) resulted in nonspecific degradation of some LMWP. Upon incubation at high temperature, the less thermostable proteases would lose their hydrolytic activity-more rapidly at higher temperatures, resulting in decreased LMWP degradation and improved production with increasing time (i.e., increasing batch number). The other, less likely, explanation would be that the amino acid cleavage-site specificity of thermolysin itself is altered due to possible conformation changes occurring due to temperature effects.

Another temperature effect that was observed is a decrease in immobilized thermolysin activity after six batch cycles at $55^{\circ} \mathrm{C}$, apparent by a reduction of LMWP area from about $29 \pm 1.5 \%$ to $25 \pm 1.0 \%$ from batch 6 to 12 , respectively. This reduction was accompanied with an increase in the protamine peak area, indicating decreased hydrolysis of the protamine substrate because of thermolysin inactivation. Although the immobilized thermolysin displayed increasing activity up to $85^{\circ} \mathrm{C}$ in the short-term temperature exposure studies previously discussed, the long-term denaturing effects at even $55^{\circ} \mathrm{C}$ were quite apparent and, therefore, higher temperatures were not pursued. From these results, it appears that $45^{\circ} \mathrm{C}$ offers the optimum condition for production of LMWP with the immobilized thermolysin. In fact, no reduction in LMWP production with immobilized thermolysin was observed at $45^{\circ} \mathrm{C}$ over a period of 7 days, determined by 21 serial batch reactions (data not shown).

\section{Continuous production of LMWP by an immobilized thermolysin PBR}

Industrial reactors can be divided into three basic groups: the batch reactor, the continuous-stirred tank reactor, and the plug-flow reactor (PFR). A PFR reactor that is filled with catalyst particles, or immobilized enzymes, is also called a PBR. In a PBR, the residence time of the substrate is much smaller than that of the enzyme, providing separation of the enzyme and its continuous use. In addition, PBRs generally provide greater control over production quality compared to batch reactors, which may yield products of varying purity from one batch to the next. We, therefore, then examined the LMWP production performance of the immobilized thermolysin in a PBR.

Because of the high enzyme loadings achieved, a very small reactor was found sufficient to achieve the required conversion of protamine. In fact, this PBR was a simple disk of 25-mm diameter and $<1 \mathrm{~mm}$ depth [see Fig. 6(A)]. Over a period of $420 \mathrm{~min}$, the production of LMWP by the PBR increased from an initial of 20 to $23 \%$, as determined by the fractional peak area [Fig. 6(B)]. Subsequent serial integration of a heparin column, for peptide purification, after the immobilized-thermolysin PBR did not result in any noticeable loss of enzymatic activity even though the immobilized thermolysin was repeatedly exposed to gradient flows containing up to $2 \mathrm{M} \mathrm{NaCl}$. Immobilization of thermolysin on GA-N-CSMG, therefore, exhibited remarkable stability and efficiency for the production of LMWP. 
A.
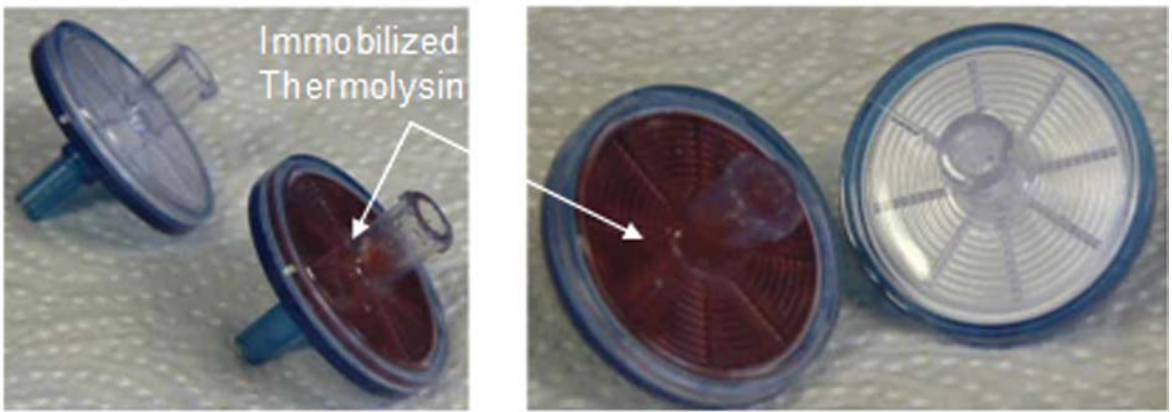

B.

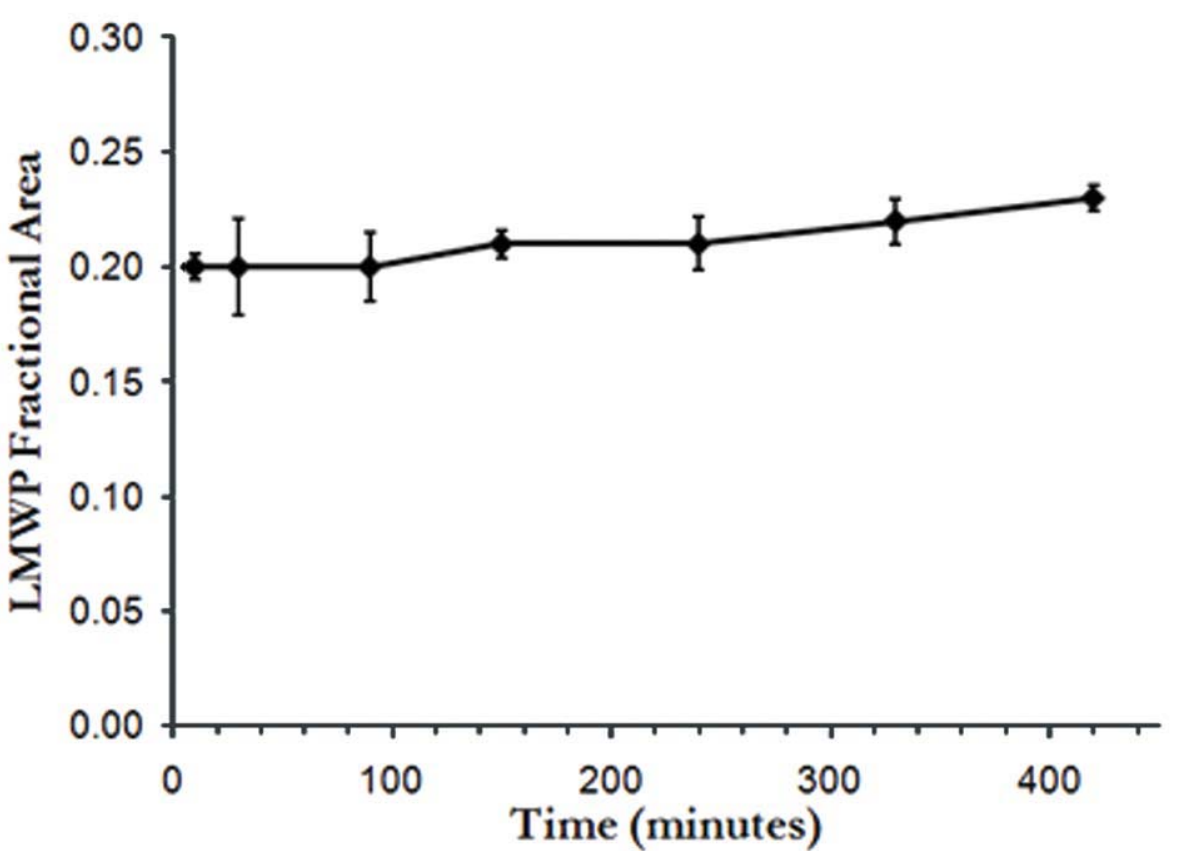

FIGURE 6. (A) Immobilized thermolysin packed-bed reactor (PBR): Syringe filter (25-mm diameter) loaded with silica particles containing immobilized thermolysin. (B) Production of LMWP with the immobilized thermolysin PBR operating at $45^{\circ} \mathrm{C}$. Fractional peak area was calculated as the ratio of LMWP peak to total peak area as eluted by salt gradient from a heparin column. Data shown as mean \pm S.D. ( $n=3$ ). [Color figure can be viewed in the online issue, which is available at wileyonlinelibrary.com.]

\section{CONCLUSIONS}

The immobilization of enzymes on functionalized silica gels offers many advantages for use in large-scale processes, including high loading capacity, improved stability, and easy recovery, and reuse of expensive enzymes. However, one of the hurdles faced by many sol-gel techniques is gel shrinkage, which reduces the effective surface area available for immobilization. Here, we demonstrated that modification of the formed sol-gel in the wet state offers significant advantages against shrinkage and helps to maintain the high surface area. The GA-N-CSMG had a measured surface area of nearly $650 \mathrm{~m}^{2} / \mathrm{g}$, which was homogenously functionalized and provided a large surface for further enzyme immobilization. Subsequent introduction of the enzyme thermolysin yielded a high loading of $733 \mathrm{mg}$ thermolysin/g matrix, much greater than other results reported in literature. The immobilized enzyme displayed improved stability over a wide $\mathrm{pH}$ range and at high temperatures. Additionally, the high immobilization loading and long-term retention of thermolysin activity allowed for efficient LMWP production with a very small reactor-enabling production of large quantities of highly pure LMWP peptide for currently ongoing preclinical safety and toxicological evaluation.

Immobilization of thermolysin on GA-N-CSMG offers great potential for large-scale peptide synthesis, and it is currently being evaluated for pilot-plant scale production of LMWP. The already established efficiency of LMWP for intracellular delivery of large cargos, combined with this costefficient, large scale production, could potentially bring to clinical practice many new promising macromolecular drugs. Additionally, the immobilized enzyme reactor could also be generally applied to the laboratory and/or commercial production of other novel peptides. 


\section{ACKNOWLEDGMENTS}

Victor C. Yang is currently a Participating Faculty in the Department of Molecular Medicine and Biopharmaceutical Sciences, Seoul National University, South Korea.

\section{REFERENCES}

1. Kane MD, Jatkoe TA, Stumpf CR, Lu J, Thomas JD, Madore SJ. Assessment of the sensitivity and specificity of oligonucleotide (50mer) microarrays. Nucleic Acids Res 2000;28:4552-4557.

2. Fisher AA, Ye D, Sergueev DS, Fisher MH, Shaw BR, Juliano RL. Evaluating the specificity of antisense oligonucleotide conjugates. J Biol Chem 2002;277:22980-22984.

3. Tidd D. Specificity of antisense oligonucleotides. Perspect Drug Discov Des 1996;4:51-60.

4. Juliano R. Challenges to macromolecular drug delivery. Biochem Soc Trans 2007;035:41-43.

5. Noguchi H, Matsumoto S. Protein transduction technology: A novel therapeutic perspective. Acta Med Okayama 2006;60:1-11.

6. Schwarze SR, Ho A, Vocero-Akbani A, Dowdy SF. In vivo protein transduction: Delivery of a biologically active protein into the mouse. Science 1999;285:1569-1572.

7. Liang JF, Yang VC. Insulin-cell penetrating peptide hybrids with improved intestinal absorption efficiency. Biochem Biophys Res Commun 2005;335:734-738.

8. Jafari M, Chen P. Peptide mediated siRNA delivery. Curr Top Med Chem 2009;9:1088-1097.

9. Torchilin VP. Tat peptide-mediated intracellular delivery of pharmaceutical nanocarriers. Adv Drug Deliv Rev 2008;60:548-558.

10. Chugh A, Eudes F, Shim YS. Cell-penetrating peptides: Nanocarrier for macromolecule delivery in living cells. IUBMB Life 2010 ; 62:183-193.

11. Fonseca SB, Pereira MP, Kelley SO. Recent advances in the use of cell-penetrating peptides for medical and biological applications. Adv Drug Deliv Rev 2009;61:953-964.

12. Chen L, Harrison SD. Cell-penetrating peptides in drug development: Enabling intracellular targets. Biochem Soc Trans 2007; 35(Part 4):821-825.

13. Temsamani J, Vidal P. The use of cell-penetrating peptides for drug delivery. Drug Discov Today 2004;9:1012-1019.

14. Chang LC, Lee HF, Yang Z, Yang VC. Low molecular weight protamine (LMWP) as nontoxic heparin/low molecular weight heparin antidote (I): Preparation and characterization. AAPS PharmSci 2001;3:E17.

15. Byun $Y$, Singh VK, Yang VC. Low molecular weight protamine: A potential nontoxic heparin antagonist. Thromb Res 1999;94:53-61.

16. Byun Y, Chang LC, Lee LM, Han IS, Singh VK, Yang VC. Low molecular weight protamine: A potent but nontoxic antagonist to heparin/low molecular weight protamine. ASAIO J 2000;46:435-439.

17. Park YJ, Liang JF, Ko KS, Kim SW, Yang VC. Low molecular weight protamine as an efficient and nontoxic gene carrier: In vitro study. J Gene Med 2003;5:700-711.

18. Park YS, Huang $Y$, Park YJ, David AE, White L, He H, Chung HS, Yang VC. Specific down regulation of 3T3-L1 adipocyte differentiation by cell-permeable antisense HIF1alpha-oligonucleotide. J Control Release 2010;144:82-90.

19. Choi YS, Lee JY, Suh JS, Kwon YM, Lee SJ, Chung JK, Lee DS, Yang VC, Chung CP, Park YJ. The systemic delivery of siRNAs by a cell penetrating peptide, low molecular weight protamine. Biomaterials 2010;31:1429-1443.

20. Park YJ, Chang LC, Liang JF, Moon C, Chung CP, Yang VC. Nontoxic membrane translocation peptide from protamine, low molecular weight protamine (LMWP), for enhanced intracellular protein delivery: In vitro and in vivo study. FASEB J 2005;19:1555-1557.

21. Kwon YM, Chung HS, Moon C, Yockman J, Park YJ, Gitlin SD, David $A E$, Yang VC. L-Asparaginase encapsulated intact erythrocytes for treatment of acute lymphoblastic leukemia (ALL). J Control Release 2009;139:182-189.

22. Moon C, Kwon YM, Lee WK, Park YJ, Yang VC. In vitro assessment of a novel polyrotaxane-based drug delivery system integrated with a cell-penetrating peptide. J Control Release 2007; 124:43-50.

23. Moon C, Kwon YM, Lee WK, Park YJ, Chang LC, Yang VC. A novel polyrotaxane-based intracellular delivery system for camptothecin: in vitro feasibility evaluation. J Biomed Mater Res A 2008;84: 238-246.

24. Suh JS, Lee JY, Choi YS, Yu F, Yang V, Lee SJ, Chung CP, Park YJ. Efficient labeling of mesenchymal stem cells using cell permeable magnetic nanoparticles. Biochem Biophys Res Commun 2009;379:669-675.

25. Chang LC, Liang JF, Lee HF, Lee LM, Yang VC. Low molecular weight protamine (LMWP) as nontoxic heparin/low molecular weight heparin antidote (II): In vitro evaluation of efficacy and toxicity. AAPS PharmSci 2001;3:E18.

26. Lee LM, Chang LC, Wrobleski S, Wakefield TW, Yang VC. Low molecular weight protamine as nontoxic heparin/low molecular weight heparin antidote (III): Preliminary in vivo evaluation of efficacy and toxicity using a canine model. AAPS PharmSci 2001;3: E19.

27. Liang JF, Zhen L, Chang LC, Yang VC. A less toxic heparin antagonist-Low molecular weight protamine. Biochemistry (Mosc) 2003;68:116-120.

28. Chang LC, Lee HF, Yang ZQ, Yang VC. Low molecular weight protamine (LMWP) as nontoxic heparin/low molecular weight heparin antidote (I): Preparation and characterization. AAPS Pharmsci 2001; 3.

29. David AE, Wang NS, Yang VC, Yang AJ. Chemically surface modified gel (CSMG): An excellent enzyme-immobilization matrix for industrial processes. J Biotechnol 2006;125:395-407.

30. Bradford MM. Rapid and sensitive method for quantitation of microgram quantities of protein utilizing principle of protein-dye binding. Anal Biochem 1976;72:248-254.

31. Zou ZC, Wei Q, Na W, Sun H, Nie ZR. Immobilization of papain on siliceous mesocellular foam. J Inorg Mater 2009;24:702-706.

32. Tischer W, Wedekind F. Immobilized Enzymes: Methods and Applications. Biocatalysis-from Discovery to Application. Berlin: Springer-Verlag Berlin; 1999. p 95-126.

33. Perry CC, Li XC. Structural studies of gel phases. I. Infrared spectroscopic study of silica monoliths-The effect of thermal history on structure. J Chem Soci Faraday Trans 1991;87:761-766.

34. De G, Kundu D, Karmakar B, Ganguli D. FTIR studies of gel to glass conversion in TEOS fumed silica-derived gels. J Non-Cryst Solids 1993;155:253-258.

35. Woignier T, Despetis F, Alaoui A, Etienne P, Phalippou J. Mechanical properties of gel-derived materials. J Sol-Gel Sci Technol 2000;19:163-169.

36. David AE, Yang AJ, Wang NS. Enzyme stabilization and immobilization by sol-gel entrapment. In: Minteer SD, editor. Enzyme Stabilization and Immobilization: Methods and Protocols. New York, NY: Humana Press; 2011. p 49-66.

37. Belyaeva AV, Smirnova YA, Lysogorskaya EN, Oksenoit ES, Timofeeva AV, Lozinskii VI, Filippova IY. Biocatalytic properties of thermolysin immobilized on polyvinyl alcohol cryogel. Russ $\mathrm{J}$ Bioorg Chem 2008;34:435-441.

38. Hoshino $\mathrm{K}$, Taniguchi M, Kawaberi $\mathrm{H}$, Takeda $\mathrm{Y}$, Morohashi $\mathrm{S}$, Sasakura T. Preparation of a novel thermo-responsive polymer and its use as a carrier for immobilization of thermolysin. J Ferment Bioeng 1997;83:246-252.

39. Guisan JM, Polo E, Aguado J, Romero MD, Alvaro G, Guerra MJ. Immobilization-stabilization of thermolysin onto activated agarose gels. Biocatal Biotransform 1997;15:159-173.

40. Clark DS. Can immobilization be exploited to modify enzyme activity? Trends Biotechnol 1994;12:439-443.

41. Matthews BW, Weaver LH, Kester WR. The conformation of thermolysin. J Biol Chem 1974;249:8030-8044.

42. Atia KS, El-Batal A. Preparation of glucose oxidase immobilized in different carriers using radiation polymerization. J Chem Technol Biotechnol 2005;80:805-811.

43. Arica MY, Hasirci V, Alaeddinoglu NG. Covalent immobilization of alpha-amylase onto PHEMA microspheres-Preparation and application to fixed-bed reactor. Biomaterials 1995;16:761-768. 